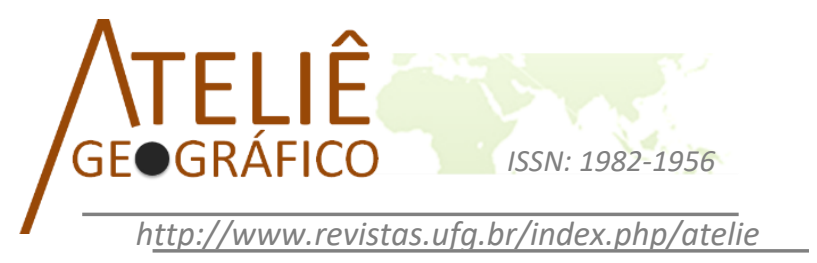

\title{
O setor sucroenergético no Triângulo Mineiro: crescimento econômico e manutenção das desigualdades sociais nas "cidades da cana"
}

\author{
El sector sucroenergético en la región del Triângulo Mineiro \\ (Brasil): crecimiento económico y permanencia de las \\ desigualdades sociales en las "ciudades de la caña" \\ The sugarcane sector in Triângulo Mineiro (Brazil): \\ economic growth and maintenance of social inequalities in \\ "sugarcane towns"
}

João Henrique Santana Stacciarini

Universidade Federal de Uberlândia - FACIP/UFU

joaostacciarini@hotmail.com

Mirlei Fachini Vicente Pereira

Universidade Federal de Uberlândia - IG/UFU

mirlei@ufu.br

\begin{abstract}
Resumo
O trabalho visou avaliar alguns antagonismos existentes no processo de expansão das atividades do setor sucroenergético (produção de cana-de-açúcar e derivados) no Triângulo Mineiro, porção oeste do estado de Minas Gerais. Tais antagonismos se expressam através de um crescimento econômico, assentado no incremento das atividades produtivas resultante da instalação de usinas sucroenergéticas nesta fração do território, em contraste com a manutenção das desigualdades sociais e da pobreza de parcela significativa da população. Tal condição pode ser verificada particularmente nos municípios mais especializados e dependentes da cultura, cujas sedes estamos reconhecendo como "cidades da cana". São avaliados aspectos do crescimento econômico resultante do ingresso da atividade em municípios especializados, bem como os que evidenciam a manutenção das desigualdades sociais e a produção de vulnerabilidades territoriais.
\end{abstract}

Palavras-chave: Setor sucroenergético, Desigualdades socioespaciais, Cidades da cana, Triângulo Mineiro. 


\begin{abstract}
Resumen
El trabajo evalúa algunos antagonismos existentes en el proceso de expansión de las actividades del sector sucroenergético (producción de caña de azúcar y derivados) en el Triângulo Mineiro, región oeste del estado de Minas Gerais (Brasil). Estos antagonismos se expresan a través de un desarrollo económico, asentado en el incremento de las actividades productivas resultante de la instalación de plantas sucroenergéticas en esta fracción del territorio, en contraste con la permanencia de las desigualdades sociales y de la pobreza de una parte significativa de la población local. Esta condición se verifica sobre todo en los municipios más especializados y dependientes de la cultura, cuyos núcleos urbanos estamos reconociendo como "ciudades de la caña". Se evaluaran aspectos del crecimiento económico resultante del ingreso de la actividad en municipios especializados, así como los aspectos que evidencian el mantenimiento de las desigualdades sociales y la producción de vulnerabilidades territoriales.

Palabras-clave: Sector sucroenergético, Desigualdades socioespaciales, Ciudades de la caña, Triângulo Mineiro (Minas Gerais, Brasil).
\end{abstract}

\begin{abstract}
The objective of this work was to evaluate some existing antagonisms in the expansion process of activities of the sugarcane industry (sugarcane production and derivatives) in Triângulo Mineiro, western region of Minas Gerais (Brazil). Such antagonisms are expressed by economic growth, based on the increase in productive activities resulting from the installation of sugarcane mills in the regional space, in contrast to the maintenance of social inequalities and the poverty of a significant amount of the population. This condition can be verified particularly in the more specialized and dependent municipalities of this crop, whose urban centers we are recognizing as "sugarcane towns". Aspects of economic growth resulting from the activity entrance in specialized municipalities are evaluated, as well as those that evidence the maintenance of social inequalities and the production of territorial vulnerabilities.

Keywords: Sugar-energy sector, Socio-spatial inequalities, Sugarcane towns, Triângulo Mineiro (Minas Gerais, Brazil).
\end{abstract}

\title{
Introdução
}

O Brasil é atualmente o maior produtor mundial de cana-de-açúcar e o maior exportador de açúcar. Em 2015, foram produzidas no país 748 milhões de toneladas de cana-de-açúcar, a partir de cultivos que ocuparam pouco mais de 10 milhões de hectares (IBGE, 2017). Também no ano de 2015, funcionavam no país 378 usinas sucroenergéticas (BRASIL, 2016b).

Tais números são expressivos e, em uma observação superficial, representam ampla fonte de renda para a União, Estados e municípios, além de riqueza gerada por grupos que controlam unidades produtivas (usinas), produtores rurais e trabalhadores do setor. Porém, diversas mazelas apresentam-se "escondidas" nas entrelinhas destes processos de produção, os quais serão analisados no decorrer deste trabalho, sobretudo os que aparecem no contexto local (na escala dos municípios). 
Neste sentido, para melhor entender o crescimento e a relevância do setor sucroenergético no país, juntamente com suas implicações territoriais, é necessário reconhecer a produção de cana-de-açúcar e derivados como uma importante atividade econômica do Brasil (desde o período colonial), que é responsável por reconfigurações territoriais que imprimem novas dinâmicas sociais no conjunto do país.

A importância da atividade canavieira na região que hoje corresponde ao Nordeste, e sua expansão, ao longo dos séculos XIX e XX, ao Rio de Janeiro e São Paulo, seguida no século XX pela afirmação da atual região Sudeste como espaço de referência para a produção sucroenergética, com os amplos incentivos do Pró-Álcool ${ }^{1}$ a partir da década de 1970, exemplificam diferentes períodos e diversas dinâmicas de uma atividade que se torna fundamental à economia brasileira.

É neste contexto de expansão e consequente busca por novas áreas que o cultivo da monocultura extrapola o oeste paulista, região tradicionalmente produtora de cana-deaçúcar pós-década de 1970 (BRAY, 1992), e se estabelece no Triângulo Mineiro (MG), fruto de um impulso do processo de reestruturação produtiva no "[...] momento em que as inovações técnicas e organizacionais assumem um caráter mais sistêmico em todo o circuito produtivo dos diversos setores econômicos" (THOMAS JÚNIOR, 2006. p. 7).

A década de 2000 indica um novo momento/período para a atividade sucroenergética no Brasil, em função das preocupações ambientais, da nova imagem do produto (o etanol) no mercado externo (figurando potencialmente como uma nova commodity global), da viabilidade dos motores flex fuel (permitindo o uso do etanol sempre que o preço é atrativo) (SAFATLE, 2011), o que ampliou sobremaneira a produção nacional, inclusive com novos agentes externos investindo na produção de combustível derivado de cana.

O resultado deste processo é uma modernização da produção e ampliação dos cultivos, com ingresso de novos capitais ao setor que, num contexto de economia financeirizada que caracteriza o Brasil das últimas décadas, permite com que a produção alcance novas regiões e amplie-se na busca de recursos naturais e humanos, implicando na ocupação de vastas áreas onde se praticava, predominantemente, uma pecuária extensiva. É a partir do início dos anos 2000 que, no contexto mundial, ocorre uma valorização expressiva das commodities agrícolas, permitindo o aumento do preço do açúcar. Especialmente após compromissos assumidos por diversos países para a redução da emissão de gases do efeito estufa no Protocolo de Quioto (1997), surgem novas perspectivas de ampliação da produção visando o mercado externo (conferindo potencialmente ao etanol alcançar a condição de commodity), o que reforça a produção

${ }^{1}$ O Pró-Álcool ou Programa Nacional do Álcool - resultante do decreto $n^{\circ} 76.593$ de 14 de novembro de 1975 - foi um programa de substituição dos combustíveis veiculares derivados de petróleo por etanol, financiado pelo governo brasileiro após a crise do petróleo de 1973 (BRASIL, 1975). 
nacional e insere novos agentes econômicos no setor, inclusive sob o comando de capitais externos e orientados por uma lógica financeira.

Os efeitos da expansão do cultivo da cana-de-açúcar no Brasil são significativos e muito mais intensos e perceptíveis no espaço de municípios especializados e em pequenas cidades, que muitas vezes são acionados para o trabalho agrícola/industrial do setor. Reproduzindo práticas já reconhecidas no estado de São Paulo, em que pequenos núcleos urbanos tornam-se verdadeiras condições de reprodução do trabalho sucroenergético (LENCIONI, 1985). Podemos reconhecer no Triângulo Mineiro a emergência de pequenas cidades muito dependentes dessa atividade, as quais reconhecemos como "cidades da cana" (PEREIRA, 2015).

Pautadas na expansão recente do setor sucroenergético, com todo o conjunto de variáveis e subsídios favoráveis à produção que tal região oferece - nas mais diferentes escalas - diversas usinas, muitas delas pertencentes a grandes grupos multinacionais, se instalam no Triângulo Mineiro em busca de oportunidades novas de acumulação. Tais empreendimentos se instalam na região de modo geral acompanhados de um discurso de desenvolvimento (e daí rapidamente legitimados pelo poder público junto à população), atribuindo ao montante de investimentos uma suposta melhora das condições materiais de vida da população. Esse discurso é normalmente defendido por políticos e lideranças locais, que se dedicam a atrair e viabilizar a instalação de empresas de grande porte.

Porém, na realidade, o que se observa são situações bastante diferentes, reveladoras das contradições inerentes à acumulação capitalista, em que a riqueza social é apropriada privadamente (HARVEY, 2014), apontando, deste modo, os limites de uma aposta de desenvolvimento a partir das atividades sucroenergéticas. O desenvolvimento "fácil e rápido" propagado em diversos discursos, se contrasta com a reprodução da pobreza e com a concentração de renda, destinando à maior parte da população o ônus que tais atividades produtivas normalmente provocam.

\section{O setor sucroenergético no Triângulo Mineiro}

A agricultura científica globalizada, caracterizada por Milton Santos (2000) pelos processos de especialização produtiva e uso intenso de fatores técnicos, científicos, informacionais e financeiros, vêm exercendo amplo domínio da produção de commodities agrícolas no Triângulo Mineiro (MG).

Particularmente desde os anos 1970, a região é acionada para produção de álcool combustível em moldes industriais, quando o cultivo da monocultura extrapola os solos paulistas e se estende para o Triângulo Mineiro, instalando-se em vastas áreas onde antes se praticavam a pecuária extensiva, a produção de gêneros alimentícios, ou ainda em áreas originalmente cobertas pelo cerrado. Vale destacar que esses rearranjos, posteriormente, consolidar-se-iam como um franco processo de reestruturação territorial produtiva, que se processa no conjunto do território nacional, sendo o Centro-Oeste do país uma região de 
franca expansão dos cultivos de cana-de-açúcar, processo que se reforça na primeira década do século atual (CASTILLO, 2015).

Ainda com relação às potencialidades do Triângulo Mineiro para acolhimento das atividades sucroenergéticas, Santos (2015) alerta para o fato dessa expansão possuir estreita ligação com atributos naturais favoráveis ao cultivo da cana-de-açúcar, como o clima quente, solo fértil, disponibilidade de água e relevo adequado à mecanização. Além de atributos geoeconômicos como sistemas de rodovias e logística, proximidade com grandes centros urbanos consumidores e exportadores, bem como ambiente políticoinstitucional "provedor" de incentivos fiscais e financeiros, parcerias público-privadas de pesquisa, dentre outros. Trata-se da conformação de uma especialização produtiva, conferindo novas condições que permitem reconhecer verdadeiros municípios canavieiros, conforme apontado por Vargas e Michelotto (2011).

Mediante tais fatores, o cultivo da cana-de-açúcar no Triângulo Mineiro ampliase consideravelmente na primeira década do século atual. Desde o ano 2000 até o ano de 2015, a área ocupada pelos canaviais expande quase cinco vezes - eram 126 mil hectares plantados em 2000, e mais de 630 mil hectares em 2015. Destaca-se ainda a concentração na região, de cerca de $70 \%$ da área plantada em todo o estado de Minas Gerais (Figura 1).

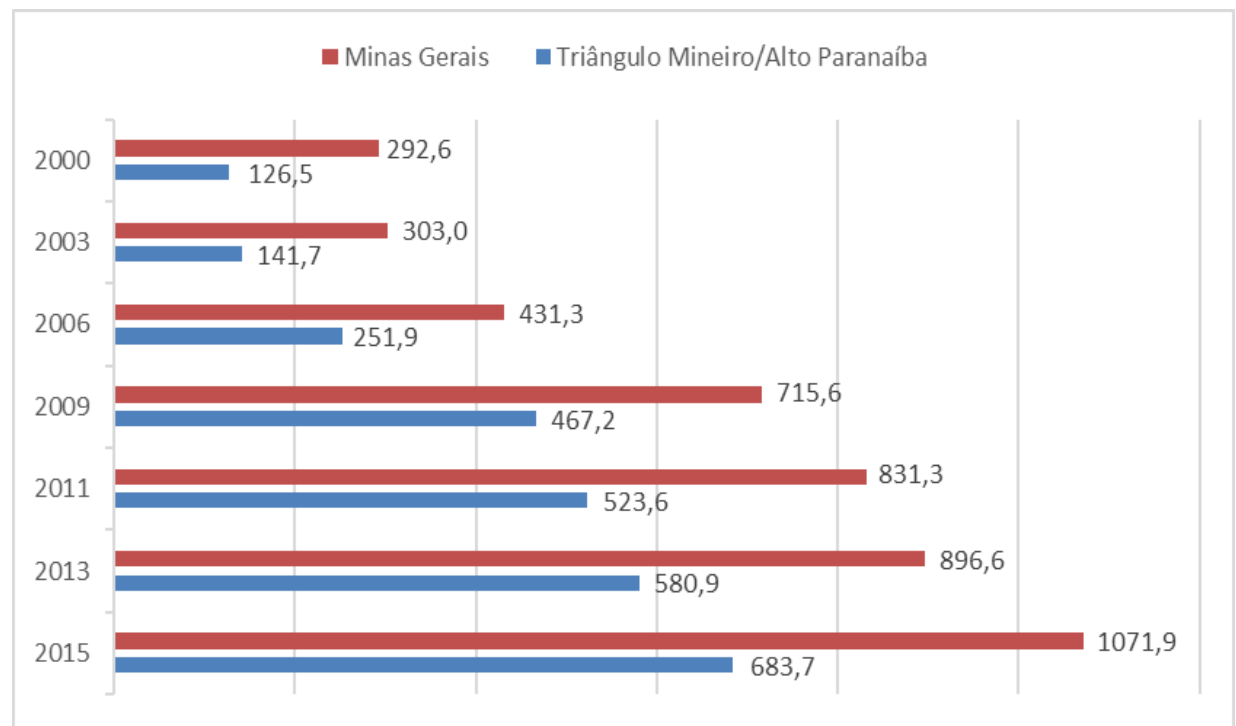

Figura 01. Área plantada com cana-de-açúcar no Estado de Minas Gerais e na Mesorregião Triângulo Mineiro/Alto Paranaíba no Período 2000-2015

Fonte: IBGE (2017). Org.: STACCIARINI, J. H. S. 
Juntamente com as condições que permitiram esse crescimento, houve amplo estímulo para a expansão do número de usinas sucroenergéticas, no âmbito da União, especialmente através de crédito barato viabilizado pelo BNDES. Em Minas Gerais, a diminuição de impostos para o consumo de etanol no estado, além de programas de potencialização da infraestrutura industrial e pavimentação de rodovias; bem como incentivos locais de menor proporção, viabilizados em diferentes municípios. Os dados disponibilizados pelo Sindicato da Indústria de Fabricação do Álcool no Estado de Minas Gerais (SIAMIG) apontam que, após o ano de 2001, 12 usinas foram inauguradas, totalizando 22 unidades em funcionamento em 19 municípios da região, e 16 projetos para novas usinas (SIAMG, 2015)2.

\section{O setor sucroenergético e as cidades da cana}

Utilizando-se uma expressão de Milton Santos (1988), pode-se dizer que o espaço regional do Triângulo Mineiro, ao longo das décadas, torna-se ainda mais funcional à produção de cana e derivados, levando à substituição de cultivos, ampliação do número de usinas sucroenergéticas e redefinição da economia urbana de um conjunto significativo de municípios que se tornam muito especializados e dependentes dessa atividade.

Neste sentido, reconhecemos como "cidades da cana" no Triângulo Mineiro (Figura 2) os pequenos núcleos urbanos, que, segundo Pereira (2015), possuem as seguintes características: são em geral marcados por pequeno efetivo populacional (com cerca de até 30 mil habitantes), detêm uma ou mais usinas sucroenergéticas em área territorial municipal, sendo que tais núcleos estão inseridos em municípios com amplo predomínio da cultura de cana em sua área territorial, quando comparada ao conjunto dos outros cultivos agrícolas (tanto os temporários quanto os permanentes), gerando paisagens monótonas que na última década ganham espaço no Triângulo Mineiro. As cidades da cana ainda possuem economia predominantemente pautada na atividade agropecuária (setor primário) ou industrial (setor secundário resultante da atuação das atividades sucroenergéticas) (PEREIRA, 2015).

Tal configuração territorial que descrevemos muito caracteriza 13 municípios no Triângulo Mineiro que foram alvo de nossa investigação, visando avaliar as potencialidades e os limites do desenvolvimento em espaços especializados nas atividades do setor sucroenergético.

2 Ainda segundo dados da SIAMIG (2015), na safra de 2013-2014, o faturamento do setor sucroenergético atinge 43,8 bilhões de dólares em todo Estado de Minas Gerais. Na safra 2014-2015 ocorreu uma moagem de 59,6 milhões de toneladas de cana-de-açúcar, responsáveis pela produção de 2,7 milhões de $\mathrm{m}^{3}$ cúbicos de etanol e 3,3 milhões de toneladas de açúcar, com destaque para o Triângulo Mineiro, principal região produtora do estado, concentrando $64 \%$ da produção de etanol e $80 \%$ de açúcar (SIAMIG, 2015). 


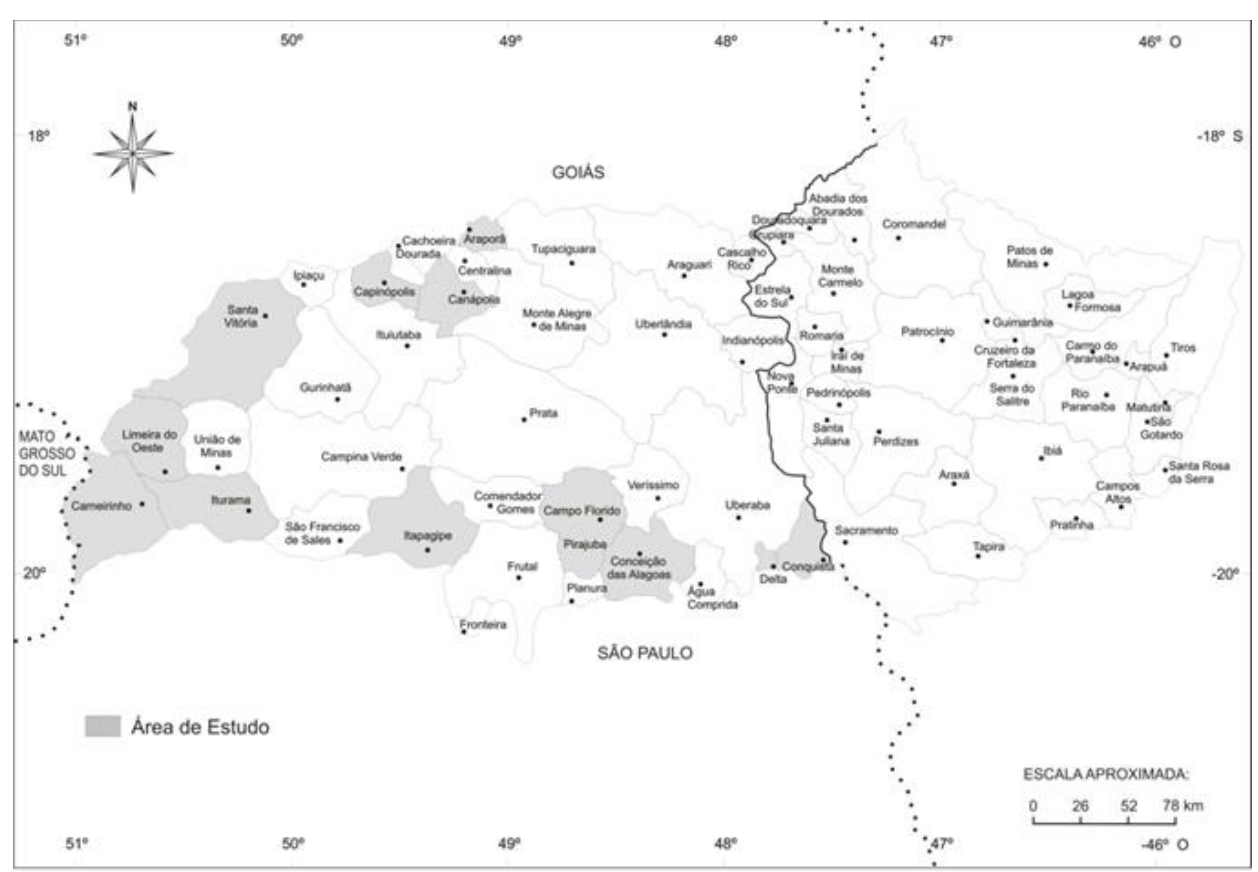

Figura 02: Localização dos Municípios estudados - mesorregião Triângulo Mineiro/Alto Paranaíba Fonte: BRITO; LIMA (2017). Elaboração: PEREIRA, M. F. V.

Vale, desta maneira, destacar a ocorrência de cenários onde o poder público e as lideranças locais desenvolvem uma "organização que permitirá produzir uma cidade cujo funcionamento será conforme ao que se espera num conjunto macroeconômico nacional reestruturado" (OSMONT, 1995. p. 281) ou ainda, a constituição de verdadeiras "empresas-cidades" (DAMIANI, 2006). Esses fatores se manifestam nos municípios avaliados, mediante um conjunto de recursos para a atração destes empreendimentos (disponibilidade de terras relativamente baratas quando da instalação de usinas, características edafoclimáticas favoráveis ao cultivo da cana-de-açúcar, mão de obra barata, aspectos logísticos favoráveis na região, entre outros). Soma-se a tal condição a manutenção de uma organização municipal que permite, muitas vezes, a empresa desfrutar de atrativos (serviços municipais) no suporte de suas atividades produtivas, levando, em alguns casos, à extrema aproximação entre empresa e município, quando os interesses corporativos se confundem com os interesses municipais. Por fim, destaca-se que o processo de industrialização da agricultura, fruto da intensificação do capital nas atividades agrícolas, rompe a "letargia" das pequenas cidades que, quando acionadas pela notória produção agrícola, ganham novos arranjos espaciais (LENCIONI, 1985). 
Os processos de especialização territorial muito caracterizam os municípios que selecionamos para a pesquisa, hoje responsáveis por $40 \%$ (19,7 milhões de toneladas) (Figura 3) de toda a produção do Triângulo Mineiro/Alto Paranaíba (49,2 milhões de toneladas em 2015).

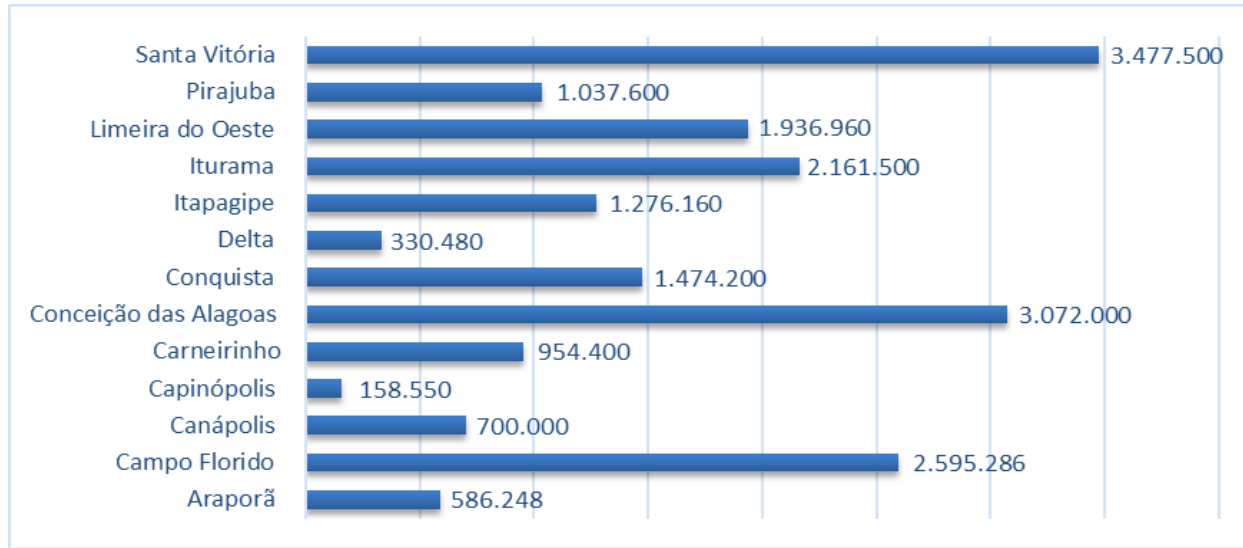

Figura 03: Produção de cana-de-açúcar nos municípios selecionados (2015)

Fonte: IBGE (2017). Org.: STACCIARINI, J. H. S.

Muitos desses municípios se especializam nas atividades sucroenergéticas na última vaga de expansão dos cultivos (início dos anos 2000), como é o caso de Santa Vitória, Limeira do Oeste, Itapagipe, Carneirinho e Campo Florido, sendo a cultura da cana-de-açúcar a de maior expressão em suas áreas agricultáveis e tendo expressão significativa dos empregos do setor (especialmente as do setor industrial) no conjunto das ocupações, permitindo assim reconhecermos situações de extrema dependência do setor sucroenergético.

\section{Crescimento econômico e manutenção das desigualdades sociais e da pobreza}

Imersos no contexto de expansão da produção brasileira, o Triângulo Mineiro e os 13 municípios que avaliamos de modo particular, conhecem forte expansão das atividades sucroenergéticas pós-anos 2000. Cabe aqui destacar, que nos municípios avaliados, cujas sedes reconhecemos como "cidades da cana", entre os anos 2000 e 2010 o número de usinas, tal como a produção de cana-de-açúcar, cresce de oito para 14 unidades ${ }^{3}$.

Outro dado expressivo é o crescimento da demanda do mercado externo pelos derivados do setor sucroenergético. Em meio ao cenário favorável que se estabelece neste

${ }^{3}$ Desde 2013, no entanto, duas usinas encontram-se desativadas, ambas unidades do grupo João Lyra, nos municípios de Canápolis e Capinópolis. 
início do século, há um crescimento de $5.732 \%$ no montante de exportações do setor nos 13 municípios avaliados, passando de US\$12,6 milhões no ano 2000, para US\$737,8 milhões em 2010 (BRASIL, 2016c), exportações em sua maioria oriundas da venda de açúcar.

Do mesmo modo, o Produto Interno Bruto (PIB) municipal (Tabela 1) é capaz de expressar o crescimento econômico verificado no período. Tal indicador econômico, representa a soma de todos os bens e serviços produzidos no município, sendo um dos parâmetros mais utilizados nos estudos econômicos quando objetiva-se quantificar o dinamismo das atividades produtivas em determinada porção territorial.

Tabela 01. Evolução do Produto Interno Bruto (PIB) municipal (em mil R\$)

\begin{tabular}{|c|c|c|c|c|}
\hline Municípios avaliados & $\mathbf{2 0 0 0}$ & $\mathbf{2 0 0 5}$ & $\mathbf{2 0 1 0}$ & $\mathbf{2 0 1 4}$ \\
\hline Araporã & 334.682 & 901.404 & 996.131 & 789.098 \\
\hline Campo Florido & 49.587 & 155.833 & 205.510 & 331.782 \\
\hline Canápolis & 116.726 & 170.583 & 208.976 & 282.447 \\
\hline Capinópolis & 86.562 & 196.351 & 206.240 & 246.225 \\
\hline Carneirinho & 56.836 & 96.949 & 167.393 & 252.388 \\
\hline Conceição das Alagoas & 129.714 & 312.832 & 490.190 & 629.004 \\
\hline Conquista & 54.327 & 93.382 & 117.839 & 181.188 \\
\hline Delta & 44.279 & 191.013 & 235.187 & 260.739 \\
\hline Itapagipe & 80.690 & 149.182 & 206.592 & 380.858 \\
\hline Iturama & 204.553 & 448.639 & 1.529 .028 & 1.535 .239 \\
\hline Limeira do Oeste & 34.902 & 69.587 & 137.010 & 208.725 \\
\hline Pirajuba & 77.843 & 79.469 & 129.898 & 198.726 \\
\hline Santa Vitória & 79.096 & 152.723 & 315.149 & 502.881 \\
\hline
\end{tabular}

Fonte: IBGE (2016). Org.: STACCIARINI, J. H. S.

Neste contexto, nota-se, conforme apresentado na Tabela 1, que o município de Limeira do Oeste, por exemplo, ao receber duas usinas, nos anos de 2005 e $2009^{4}$ (STACCIARINI; PEREIRA, 2015), vê o seu PIB multiplicar-se três vezes, num período de cinco anos (2005-2010), alcançando ainda posteriormente um maior crescimento à medida em que a produção agrícola e agroindustrial aumenta. No município de Campo Florido a situação foi semelhante. Após receber sua primeira usina sucroenergética, no ano de 2002, o PIB municipal cresce seis vezes até o ano de 2014.

Essa mesma situação se repete em Santa Vitória (usinas com primeiras safras em 2008 e 2009) e Itapagipe (uma usina instalada em 2006), que conhecem significativo incremento do PIB municipal. Tal crescimento se repete também nas localidades em que as antigas usinas passaram a ser controladas por grupos maiores e mais capitalizados, onde

\footnotetext{
${ }^{4}$ Informações sobre grupos atuantes, datas de fundação, anexação ou desmembramento de unidades produtivas nesta porção do território estão disponíveis em Stacciarini e Pereira (2015).
} 
ocorre aumento do processamento da cana (STACCIARINI; PEREIRA, 2015). Desta forma, o município de Delta também conhece crescimento significativo neste início de século, somando nova condição produtiva após a antiga usina (que funcionava desde a década de 1950) ser adquirida por um grupo oriundo do estado de Alagoas (atualmente controlada pelo grupo Delta Sucroenergia).

Tomando a soma do PIB dos 13 municípios avaliados, observa-se que eles cresceram em média $429 \%$ no intervalo de 2000 a 2014, enquanto a inflação acumulada no período foi de $138,7 \%$ (IPCA/IBGE). Deste modo, fica evidente o crescimento da produção de riquezas nos municípios pesquisados (ainda que muitas vezes custeadas ou subsidiadas pelo próprio Estado, através da oferta de crédito e infraestruturas).

Porém, uma análise dos dados socioeconômicos nos permite afirmar que, mesmo diante de vultosos incrementos à economia local durante toda a primeira década do século atual, que representam significativos ganhos para os agentes do setor nesta porção do território brasileiro, é notória a manutenção das condições de desigualdade social e pobreza de grande parcela da população nos municípios que pesquisamos no Triângulo Mineiro, revelando que a aposta nas atividades do setor sucroenergético não confere melhoria nas condições materiais de vida da população mais pobre.

O gráfico a seguir (Figura 4) indica a porcentagem da população de baixa renda ${ }^{5}$ nos municípios estudados, referente ao ano de $2010^{6}$. Os dados levantados permitem a observação de que quase um quarto da população destes municípios é caracterizada como população de baixa renda.

O município de Limeira do Oeste, por exemplo, apesar de ser o único com duas centrais produtivas 7 - o que lhe garantiria potencialmente retorno financeiro para supostas melhorias nas condições materiais de vida aos seus habitantes - ter 18.000 hectares ocupados com o cultivo de cana-de-açúcar e produzir cerca de 1,5 milhões de toneladas da cultura no ano de 2010 (IBGE, 2017), é o detentor de expressiva população com baixa renda $(29,37 \%)$ e residências sem abastecimento de água $(32,10 \%)$; além de contar com uma taxa de analfabetismo de $11,20 \%$ (Tabela 2). No mesmo município, em abril do ano de 2009 foram encontrados 184 trabalhadores em situação de trabalho análogo ao escravo em uma fazenda da Usina Cabrera Central Energética, pertencente ao ex-ministro da agricultura Antonio Cabrera (no governo de Fernando Collor de Melo, 1990-1992). Na

${ }^{5}$ Como População de Baixa Renda entende-se a proporção (\%) da população residente com renda domiciliar mensal per capita de até meio salário mínimo, em determinado espaço geográfico, no ano considerado (BRASIL, 2016a).

${ }^{6}$ Por questões metodológicas, optou-se pela avaliação dos dados referentes ao ano de 2010 . Tal escolha se justifica pelo fato deste ser o último ano em que foi realizado o censo demográfico brasileiro, permitindo a comparação de dados nas diferentes variáveis.

${ }^{7}$ Limeira do Oeste recebe no ano de 2005, uma unidade produtiva do grupo Tércio Wanderley. Em 2009, uma nova unidade é instalada no município, a Cabrera Central Energética, investimento do grupo Cabrera e da multinacional Archer Daniels Midland, controlada pela ADM desde o ano de 2011. 
ocasião, Antônio Cabrera, junto do grupo Archer Daniels Midland (ADM), era sócio de uma usina sucroenergética localizada em Limeira do Oeste8. Assim, a riqueza gerada pelo setor é extremamente concentrada e implica na manutenção de esquemas arcaicos de exploração do trabalho, resultando, portanto, em manutenção da pobreza.

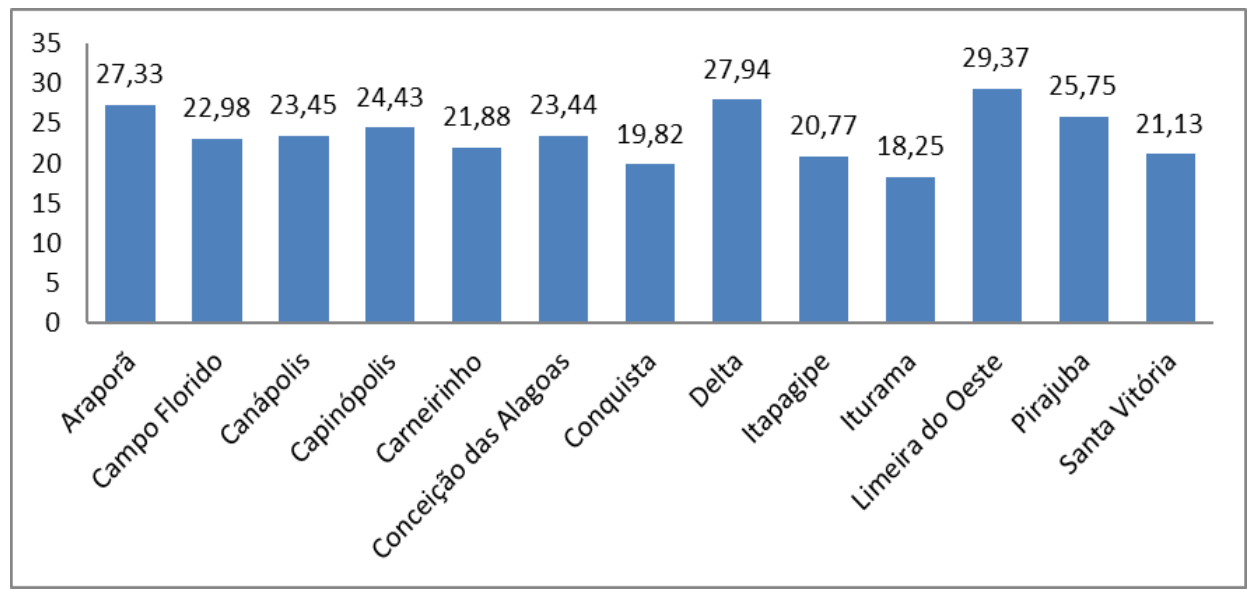

Figura 04: Porcentagem da população de baixa renda nos municípios estudados (2010). Fonte: BRASIL (2016a). Org.: STACCIARINI, J. H. S.

Situação similar pode ser encontrada nos municípios de Conceição das Alagoas e Pirajuba, onde a manutenção das condições de desigualdade social e pobreza é emblemática, mesmo há mais tempo acionados pelo setor sucroenergético. Conceição das Alagoas acolhe, desde 1996, uma unidade produtiva, a Usina Caeté (unidade Volta Grande) ${ }^{9} ; 14$ anos depois (2010) o município torna-se o $11^{\circ}$ maior produtor de cana-deaçúcar do Brasil (41.500 hectares com a cultura, com produção superior a 3,8 milhões de ton.) (IBGE, 2017). Apesar da notória produção, concentra indicadores socioeconômicos expressivos da situação de vulnerabilidade social - no mesmo ano de 2010, 23,4\% da população integrava o estrato de baixa renda, $18,8 \%$ das famílias dependiam do Programa Bolsa Família do governo federal, 9,6\% da população não possuía abastecimento de água, além de uma taxa de analfabetismo que alcançava 8,3\% (Tabela 2).

O município de Pirajuba, um dos menos populosos dentre os que avaliamos (4.656 habitantes em 2010) é o que possuía a maior porcentagem de área plantada em relação a sua extensão territorial. Dos $337,98 \mathrm{~km}^{2}$ pertencentes ao município, $140 \mathrm{~km}^{2}$

${ }^{8}$ Conforme denúncia do Ministério do Trabalho, empregados viviam em alojamentos precários, eram submetidos a jornadas de trabalho exaustivas, não tinham acesso à água potável e a equipamentos de proteção individual (EPI), entre outras irregularidades (HASHIZUME, 2009).

${ }^{9}$ As unidades da sociedade instaladas em Minas Gerais passaram a ser controladas pelo Grupo Delta Sucroenergia em 2010 (DELTA SUCROENERGIA, 2016). 
(14.000 hectares) eram ocupados com o cultivo da cana-de-açúcar em 2010 (IBGE, 2017), mais de $40 \%$ de sua área territorial. Entretanto, e apesar da presença de uma usina operando em seu território desde 1984 (Usina Santo Ângelo), a população de baixa renda correspondia a um quarto do total de habitantes, além do maior índice de Razão de Renda ${ }^{10}$ entre os municípios avaliados $(21,01)$, o que nos permite concluir que a geração de riqueza pelo setor não é acompanhada de distribuição de renda. Destaca-se ainda que, no período entre 2000 e 2010, o cultivo de cana-de-açúcar no município dobra de volume, mas com um crescimento acompanhado da ampliação da desigualdade, uma vez que a Razão de Renda ampliou de 14,16 para 21,01 no mesmo período (BRASIL, 2016a), revelando a concentração da riqueza.

O fato é que todos os municípios avaliados, apesar de concentrarem grande produção de cana-de-açúcar e sediarem usinas em seu território municipal, ainda sim guardam profundas desigualdades socioeconômicas, marcadas pela concentração de renda. Neste sentido, Camelini (2011) aponta que a produção destas riquezas se caracteriza pela concentração de recursos nas mãos daqueles que controlam os recursos territoriais e pela exclusão de parcela significativa da população.

São claras as implicações territoriais da especialização territorial produtiva, com características intrínsecas ao setor sucroenergético, já bem apontadas por Castillo (2013, 2015). Há necessidade de plantio significativo de cana-de-açúcar em áreas próximas às usinas, inviabilizando ou desestimulando a realização de outras atividades agrícolas. A particularidade de um ciclo vegetativo marcado pela semiperenidade (ciclos de cinco anos) implica em esquemas que subordinam por longo tempo proprietários de terras seduzidos pela renda fácil oriunda dos arrendamentos. Tais condições figuram como base para a criação de um engessamento do território (CASTILLO, 2013, p.78), que reforça a especialização e a dependência econômica do setor que, como num círculo vicioso, impossibilita a diversificação produtiva em contextos de cidades pequenas, como é o caso das cidades da cana no Triângulo Mineiro. Assim, como esperar que outras atividades ou novas possibilidades de trabalho e de geração de renda surjam nestes lugares?

É deste modo que, no ano de 2010, nos 13 municípios avaliados no Triângulo Mineiro, que são muito marcados pela especialização produtiva que atende o setor sucroenergético, em média, 23,5\% da população sobrevivia com baixa renda, 20,4\% recebiam auxílios do programa Bolsa Família, 17,5\% das residências não possuíam abastecimento de água, além de contarem com $10 \%$ de taxa de analfabetismo e uma Razão da Renda de $13,7 \%$ (Tabelas 2 e 3).

\footnotetext{
${ }^{10}$ Número de vezes que a renda agregada do quinto superior da distribuição da renda (20\% mais ricos) é maior do que a renda do quinto inferior (20\% mais pobres) na população residente em determinado espaço geográfico, no ano considerado (BRASIL, 2016a).
} 
Tabela 02: Indicadores Socioeconômicos dos municípios avaliados (2010)

\begin{tabular}{|c|c|c|c|c|}
\hline $\begin{array}{c}\text { Municípios } \\
\text { avaliados }\end{array}$ & $\begin{array}{c}\text { População } \\
\text { de Baixa } \\
\text { Renda (\%) }\end{array}$ & $\begin{array}{c}\text { Razão da } \\
\text { Renda } \\
(\%)\end{array}$ & $\begin{array}{c}\text { Taxa de } \\
\text { analfabetismo } \\
(\boldsymbol{\%})\end{array}$ & $\begin{array}{c}\text { Residências } \\
\text { sem } \\
\text { abastecimento } \\
\text { de água (\%) }\end{array}$ \\
\hline Araporã & 27,33 & 9,05 & 8,40 & 4,74 \\
\hline Campo Florido & 22,98 & 15,53 & 8,50 & 27,70 \\
\hline Canápolis & 23,45 & 12,11 & 14,20 & 12,26 \\
\hline Capinópolis & 24,43 & 18,79 & 12,20 & 8,69 \\
\hline Carneirinho & 21,88 & 14,72 & 11,50 & 30,34 \\
\hline Conceição das Alagoas & 23,44 & 15,38 & 8,30 & 9,65 \\
\hline Conquista & 19,82 & 9,84 & 8,40 & 15,17 \\
\hline Delta & 27,94 & 10,09 & 13,10 & 7,68 \\
\hline Itapagipe & 20,77 & 13,08 & 6,90 & 31,03 \\
\hline Iturama & 18,25 & 11,12 & 8,40 & 14,06 \\
\hline Limeira do Oeste & 29,37 & 16,52 & 11,20 & 32,10 \\
\hline Pirajuba & 25,75 & 21,01 & 7,90 & 14,61 \\
\hline Santa Vitória & 21,13 & 10,95 & 11,60 & 20,55 \\
\hline
\end{tabular}

Fonte: BRASIL (2016a); IBGE (2016). Org.: STACCIARINI, J. H. S.

Os indicadores socioeconômicos refletem ainda sérios problemas de gestão urbana nessas cidades da cana. Neste sentido, Lencioni (1985) alertou, desde a década de 1980, que a intensificação do capital nas atividades agrárias modificava o espaço urbano, ampliando a dimensão de seus problemas, mesmo em núcleos de pequena dimensão. A exemplo disto nota-se o surgimento e incremento das periferias urbanas, denunciando a manutenção e mesmo a ampliação da pobreza e das desigualdades sociais. O trabalhador rural, que agora habita as periferias da cidade, atuou como boia fria (DAMIANI, 2006) e hoje, no contexto de mecanização do corte, emprega-se em trabalhos em geral mal remunerados e, também recentemente, tornou-se dependente dos programas governamentais de auxílio social.

Como resultado deste processo, observa-se a ampliação da concessão de benefícios oriundos do poder público, tais como o Programa de Transferência Direta de Renda Bolsa Família ${ }^{11}$ (Tabela 3), disponibilizado através de parceria dos governos federal e municipal, na tentativa de diminuir a pobreza e oferecer condições básicas para as famílias carentes.

${ }^{11}$ O Bolsa Família é um programa de transferência direta de renda, direcionado às famílias em situação de pobreza e de extrema pobreza em todo o país. O programa busca garantir a essas famílias o direito à alimentação e o acesso à educação e à saúde (CAIXA ECONÔMICA FEDERAL, 2016a). 
Tabela 03: Dados e Indicativos do Programa Bolsa Família (2010)

\begin{tabular}{|c|c|c|c|c|}
\hline $\begin{array}{c}\text { Municípios } \\
\text { avaliados }\end{array}$ & $\begin{array}{c}\text { Repasses do } \\
\text { governo federal } \\
\text { (em R\$) }\end{array}$ & $\begin{array}{c}\text { Total de } \\
\text { domicílios } \\
\text { existentes }\end{array}$ & $\begin{array}{c}\text { Famílias } \\
\text { atendidas }\end{array}$ & $\begin{array}{c}\text { \% de famílias } \\
\text { atendidas do total } \\
\text { de domicílios }\end{array}$ \\
\hline Araporã & $297.844,00$ & 1.795 & 301 & 16,77 \\
\hline Campo Florido & $538.531,00$ & 2.166 & 493 & 22,76 \\
\hline Canápolis & $487.293,00$ & 3.688 & 712 & 19,31 \\
\hline Capinópolis & $896.402,00$ & 4.982 & 1.231 & 24,71 \\
\hline Carneirinho & $737.214,00$ & 3.253 & 790 & 24,29 \\
\hline $\begin{array}{c}\text { Conceição das } \\
\text { Alagoas }\end{array}$ & $1.095 .137,00$ & 6.956 & 1.313 & 18,88 \\
\hline Conquista & $274.187,00$ & 2.083 & 410 & 19,68 \\
\hline Delta & $398.992,00$ & 2.382 & 483 & 20,28 \\
\hline Itapagipe & $855.848,00$ & 4.402 & 962 & 21,85 \\
\hline Iturama & $1.985 .950,00$ & 11.112 & 1.949 & 17,54 \\
\hline Limeira do Oeste & $157.667,00$ & 2.277 & 229 & 10,06 \\
\hline Pirajuba & $262.690,00$ & 1.506 & 242 & 16,07 \\
\hline Santa Vitória & $1.299 .465,00$ & 6.103 & 1.640 & 26,87 \\
\hline
\end{tabular}

Fonte: BRASIL (2010); IBGE (2016). Org.: STACCIARINI, J. H. S.

Desta forma, no ano de 2010, estes 13 municípios receberam juntos de $\mathrm{R} \$ 9,3$ milhões, montante que é repassado a 10.755 famílias e que resulta em uma média de R\$ $\mathrm{R} \$ 71,96 /$ mês por família atendida. O valor, significativamente baixo, expressa a dependência e a vulnerabilidade que as famílias se encontram. Destaca-se ainda que, como abordado anteriormente, mais de $20 \%$ das famílias residentes nestes municípios recebem o benefício. É essa a condição da população mais pobre que habita as pequenas cidades imersas numa região marcada pela presença da agricultura científica globalizada (SANTOS, 2000), responsável pela produção de um dos setores que mais recebera financiamentos do BNDES nesta primeira década do século.

Ainda como traço da vulnerabilidade e das desigualdades sociais no meio urbano nessas cidades da cana, podemos apontar a carência de moradias destinadas à população de baixa renda, através da análise dos dados referentes ao Programa Minha Casa, Minha Vida (PMCMV) ${ }^{12}$ - exclusivamente os da chamada Faixa I (voltados para as famílias com rendimento mensal de até $\mathrm{R} \$ 1,6 \mathrm{mil})$, bem como os do programa da Companhia de

12 O Programa Minha Casa, Minha Vida (PMCMV) criado em março de 2009 pelo Governo Federal, possui opção de financiamento especialmente voltada para famílias com renda mensal de até $\mathrm{R} \$ 1,6$ mil (na modalidade Faixa I) (CAIXA ECONÔMICA FEDERAL, 2016b). 
Habitação do Estado de Minas Gerais (COHAB), também responsável por atender famílias em condições de vulnerabilidade social.

O que se revela - de maneira similar aos indicadores socioeconômicos - e mesmo diante do expressivo incremento da produção no setor sucroenergético nos municípios avaliados, são as contradições no discurso de crescimento econômico e desenvolvimento para a população, uma vez que parcela relevante dos habitantes dos municípios estudadas necessitavam ou ainda necessitam de programas públicos para acessar a habitação. Deste modo (Tabela 4), no período de 2006 a 2015, 4.417 habitações populares foram entregues nas 13 cidades da cana avaliadas no Triângulo Mineiro.

Tabela 04: Residências entregues pelos Programas Minha Casa, Minha Vida (Faixa 1) e Companhia de Habitação do Estado de Minas Gerais, entre 2006 e 2015

\begin{tabular}{|c|c|c|c|}
\hline $\begin{array}{c}\text { Municípios } \\
\text { avaliados }\end{array}$ & $\begin{array}{c}\text { COHAB } \\
\text { (Estado } \\
\text { de MG) }\end{array}$ & $\begin{array}{c}\text { Minha Casa, } \\
\text { Minha Vida } \\
\text { (governo federal) }\end{array}$ & $\begin{array}{c}\text { Total de } \\
\text { habitações } \\
\text { entregues }\end{array}$ \\
\hline Araporã & - & 150 & 150 \\
\hline Campo Florido & 150 & 142 & 292 \\
\hline Canápolis & 162 & - & 162 \\
\hline Capinópolis & 80 & $* 515$ & 595 \\
\hline Carneirinho & 120 & - & 120 \\
\hline Conceição das Alagoas & - & 523 & 523 \\
\hline Conquista & 50 & $* * 250$ & 300 \\
\hline Delta & - & 110 & 110 \\
\hline Itapagipe & 100 & - & 100 \\
\hline Iturama & 332 & 725 & 1057 \\
\hline Limeira do Oeste & 50 & $* * 258$ & 308 \\
\hline Pirajuba & 100 & 240 & 340 \\
\hline Santa Vitória & 60 & $* * 300$ & 360 \\
\hline
\end{tabular}

*315 unidades entregues e 200 em processo de finalização.

** unidades em construção.

Fonte: COHAB (2016); BRASIL (2016); CEF (2016b). Org.: STACCIARINI, J. H.

Em Iturama, a produção sucroenergética é consolidada desde os anos 1980 (usina instalada em seu território desde $1985^{13}$ ). Em 2010, o município figurava dentre os maiores produtores de cana-de-açúcar de Minas Gerais (quarto maior produtor, com 2,3 milhões de toneladas e 30,9 mil hectares) (IBGE, 2016). Ele é o mais populoso dos municípios estudados e também o que recebeu maior número de unidades habitacionais

${ }^{13}$ Uma usina, incorporada pelo Grupo Tércio Wanderley no ano de 1994. 
dos programas governamentais; um total de 1.057 unidades (Tabela 4). Em Conquista, onde a produção de cana de açúcar e derivados ocorre há mais de um século ${ }^{14}$, o déficit habitacional era de tal modo significativo que, no período avaliado, 300 habitações populares foram inauguradas, o que corresponde a aproximadamente $13 \%$ do total de domicílios do município (IBGE, 2016). Em Campo Florido $\left(9^{\circ}\right.$ maior produtor de cana no ano de 2010), os conjuntos habitacionais da COHAB-MG e do Minha Casa, Minha Vida, entregues no período, representam cerca de $12 \%$ dos domicílios municipais.

Disto podemos deduzir que, mesmo nestas pequenas cidades em que as ofertas do consumo são reduzidas e o custo de vida tende a ser baixo, a situação expressa pelo déficit habitacional revela o quanto a remuneração do trabalho no setor é incapaz de garantir dignidade aos trabalhadores (acesso a casa própria), conferindo-lhes condições mínimas de sobrevivência e uma reprodução social marcada por um conjunto significativo de carências materiais. Sendo assim, como esperar um desenvolvimento dos municípios a partir da riqueza gerada pelo setor sucroenergético?

\section{Considerações finais}

A expansão do cultivo da cana-de-açúcar e da produção de derivados como açúcar e etanol ocorre de forma significativa neste início de século, aumentando exponencialmente o faturamento do setor sucroenergético e as exportações do país, ainda que isso reforce a condição subordinada do Brasil, como fornecedor mundial de commodities. Se os efeitos de tal expansão à economia brasileira são, à primeira vista, significativos, sérias implicações territoriais caras aos espaços acionados para a produção são inevitáveis. Nos municípios mais especializados e mesmo dependentes do setor sucroenergético no Triângulo Mineiro, o volume de investimentos do setor e os ganhos resultantes da produção são incapazes de resolver problemas que persistem no campo e nas pequenas cidades que aqui reconhecemos como cidades da cana.

De fato, observa-se uma ampliação da riqueza produzida nos municípios avaliados. É neste sentido que entre os anos 2000 e 2010, nota-se a ampliação do número de usinas de oito para 14 unidades e um aumento da produção de cana-de-açúcar, que expande de 7,4 milhões de toneladas para 19 milhões de toneladas produzidas, resultantes do cultivo de 225,5 mil hectares plantados no ano de 2010 (IBGE, 2017). Tal crescimento econômico se mostra ainda mais evidente quando se analisa a ampliação do PIB nos municípios estudados.

Aos olhos do Estado, as atividades sucroenergéticas que se expandiram nas últimas décadas no Triângulo Mineiro portam-se como indutoras de desenvolvimento, seja pelos vultosos investimentos na região ou pela riqueza gerada. Contudo, os problemas

\footnotetext{
${ }^{14}$ A produção de açúcar em moldes industriais ocorre na área atual do município de Conquista desde 1904. A usina de Conquista foi incorporada, através de arrendamento, ao Grupo Delta Sucroenergia em 2011 (STACCIARINI; PEREIRA, 2015).
} 
sociais que assolam as pequenas cidades ainda permanecem e muito se expressam, seja pela desigualdade de renda, necessidade de acesso à programas de assistência social, expressiva demanda de moradias, entre outros problemas. Assim, essa é uma realidade que implica em reconhecermos os limites do desenvolvimento em municípios muito dependentes das atividades do setor. Neste contexto, os dados levantados permitem observar que, apesar do significativo crescimento econômico, pautado na ampliação das atividades sucroenergéticas, em média, quase um quarto da população dos municípios analisados se enquadra como população de baixa renda.

Por tudo que foi apresentado, transparece que o crescimento da produção de derivados de cana-de-açúcar nos municípios citados do Triângulo Mineiro não consegue assegurar o desenvolvimento e tampouco garante distribuição de renda para os seus habitantes, mesmo sendo os núcleos urbanos pequenos e pouco populosos. A face geográfica das cidades da cana é, assim, marcada pela dependência do setor sucroenergético e pelas desigualdades sociais. Urge o Estado exigir compensações em regiões especializadas e tomar posturas que permitam reverter os esquemas de monopólio das atividades do setor, viabilizando possibilidades de diversificação do trabalho e garantindo formas outras de geração de renda nestes municípios.

\section{Agradecimentos}

O artigo resulta de pesquisa realizada com auxílio financeiro da Fundação de Amparo à Pesquisa do Estado de Minas Gerais - FAPEMIG (APQ-01797-14) e bolsa de Iniciação Científica do CNPq/UFU (CNPq2015-HUM015).

\section{Referências}

BRASIL. Decreto $n^{\circ} 76.593$, de 14 de novembro de 1975. Institui o Programa Nacional do Álcool e dá outras Providências. Senado Federal. Disponível em: < http://www2.camara.leg.br/legin/fed/decret/1970-1979/decreto-76593-14-novembro1975-425253-publicacaooriginal-1-pe.html>. Acesso em: 29 mar. 2016.

BRASIL. Departamento de Informática do Sistema Único de Saúde (DATASUS). Informações de Saúde (TABNET): demográficas e socioeconômicas. 2016a. Disponível em: <http://www2.datasus.gov.br/DATASUS/index.php?area=0206>. Acesso em: 21 fev. 2016.

BRASIL. Ministério da Agricultura, Pecuária e Abastecimento. 2016b. Disponível em: <www.agricultura.gov.br>. Acesso em: 05 dez. 2016.

BRASIL. Ministério do Desenvolvimento, Indústria e Comércio Exterior. Balança Comercial Brasileira por Município. 2016c. Disponível em: <http://www.mdic.gov.br/sitio/sistema/balanca/?item=2013-12>. Acesso em: 21 mar. 2016. 
BRAY, S. C. O Proálcool e as transformações nas áreas canavieiras do estado de São Paulo. Boletim de Geografia Teorética, Rio Claro, v. 22, n. 43-44, p.21-26, 1992.

CAIXA ECONÔMICA FEDERAL. Programa Bolsa Família. 2016a. Disponível em: <http://www.caixa.gov.br/programas-sociais/bolsa-familia/Paginas/default.aspx>. Acesso em: 4 Dez. 2016.

CAIXA ECONÔMICA FEDERAL. Programa Minha Casa, Minha Vida. $2016 \mathrm{~b}$. Disponível em: 〈http://www.caixa.gov.br/voce/habitacao/minha-casa-minha-vida〉. Acesso em: 04 dez. 2016.

CAMELINI, J. H. Regiões competitivas do etanol e vulnerabilidade territorial no Brasil: o caso emblemático de Quirinópolis, GO. 2011. 159 f. Dissertação (Mestrado) Instituto de Geociências, Universidade Estadual de Campinas, Campinas, 2011.

CASTILLO, R. A expansão do setor sucroenergético no Brasil. In: BERNARDES, J. A.; SILVA, C. A.; ARRUZZO, R. C. (Org.). Espaço e energia: mudanças no paradigma sucroenergético. Rio de Janeiro: Lamparina, 2013. p.75-84.

CASTILLO, R. Dinâmicas recentes do setor sucroenergético no Brasil: competitividade regional e expansão para o bioma Cerrado. GEOgraphia (UFF), Niterói, v. 17, n. 35, p. 95-119, 2015.

COHAB. Companhia de Habitação do Estado de Minas Gerais - Cohab Minas. 2016. Disponível em: <http://www.cohab.mg.gov.br>. Acesso em: 10 jun. 2016.

DAMIANI, A. L. Cidades médias e pequenas no processo de globalização: apontamentos bibliográficos. In: LEMOS, M. I. G.; ARROYO, M.; SILVEIRA, M. L. (Org.). América Latina: cidade, campo e turismo. São Paulo: CLACSO, 2016. p. 135147.

DELTA SUCROENERGIA. Delta Sucroenergia. Disponível em: <http://www.deltasucroenergia.com.br>. Acesso em: 21 fev. 2016.

HARVEY, D. Diecisiete contradiciones y el fin del capitalismo. Quito: Editorial IAEN, 2014.

HASHIZUME, M. Após flagra, ex-ministro da Agricultura ataca fiscalização. Repórter Brasil, São Paulo, 15 jun. 2009. Disponível em: $<$ http://reporterbrasil.org.br/2009/06/apos-flagra-ex-ministro-da-agricultura-atacafiscalizacao>. Acesso em: 23 fev. 2016.

IBGE. Instituto Brasileiro de Geografia e Estatística. PAM - Produção agrícola municipal. Disponível em: <https://sidra.ibge.gov.br/tabela/1612>. Acesso em: 20 fev. 2017.

IBGE. Instituto Brasileiro de Geografia e Estatística. IBGE Cidades (Séries Estatísticas). Disponível em: <www.cidades.ibge.gov.br>. Acesso em: 21 jan. 2016. 
LENCIONI, S. Agricultura e urbanização: a intensificação do capital na agricultura e a nova relação rural urbano no estado de São Paulo. Revista do Departamento de Geografia da USP, São Paulo, v. 4, p.41-51, 1985.

OSMONT, A. La banque mondiale et lês villes: du développement à l'ajustement. Paris: Karthala, 1995.

PEREIRA, M. F. V. As 'cidades da cana' no Triângulo Mineiro (Brasil): para uma discussão das implicações territoriais do agronegócio e de seus nexos urbanos. In: ENCUENTRO DE GEÓGRAFOS DE AMÉRICA LATINA, 15., 2015, La Habana. Anais... La Habana: Universidad La Habana, 2015.

SAFATLE, F. N. A economia política do etanol. São Paulo: Alameda, 2011.

SANTOS, H. F. Agricultura científica globalizada e implicações socioambientais: alguns apontamentos a partir da expansão do setor sucroenergético na Mesorregião Triângulo Mineiro/Alto Paranaíba. In: SIMPÓSIO INTERNACIONAL DE GEOGRAFIA AGRÁRIA, 7., 2015, Goiânia. Anais... Anais... Goiânia: Universidade Federal de Goiás, 2015. p. 195-209.

SANTOS, M. Metamorfoses do espaço habitado. São Paulo: Hucitec, 1988.

SANTOS, M. Por uma outra globalização: do pensamento único à consciência universal. Rio de Janeiro: Record, 2000.

SIAMIG. Sindicato da Indústria da Fabricação do Álcool no Estado de Minas Gerais. Números do setor sucroenergético brasileiro. 2015. Disponível em: <www.siamig.com.br/cache/Documentos/perfilproducaosite.pdf >. Acesso em: 26 jun. 2016.

STACCIARINI, J. H. S; PEREIRA, M. F. V. Implicações territoriais do setor sucroenergético no Triângulo Mineiro: inserção e limites da "vocação" exportadora. In: SIMPÓSIO INTERNACIONAL DE GEOGRAFIA AGRÁRIA, 7., 2015, Goiânia. Anais... Goiânia: Universidade Federal de Goiás, 2015. p.3531-3546.

THOMAS JÚNIOR, A. Reestruturação produtiva do capital no campo, no século XXI, e os desafios para o trabalho. Scripta Vetera, 2006. Disponível em: <www.ub.edu/geocrit/sv-87.htm>. Acesso em: 21 mar. 2016.

VARGAS, G. M.; MICHELOTTO, B. D. G. Novas dinâmicas regionais: as consequências da expansão da cultura da cana-de-açúcar no Triângulo Mineiro. Geografia, Rio Claro, v. 36, n. 1, p. 5-22, 2011. 


\section{João Henrique Santana Stacciarini}

Professor substituto no curso de Geografia da Universidade Federal de Uberlândia. Mestrando no Programa de Pós-Graduação em Geografia da Universidade Federal de Uberlândia e licenciado em Geografia pela mesma universidade.

Av. João Naves de Ávila, 2121, Instituto de Geografia, Campus Santa Mônica, UFU, Uberlândia, Minas Gerais. CEP: 38.400-902

E-mail: joaostacciarini@hotmail.com

\section{Mirlei Fachini Vicente Pereira}

Doutor em Geografia pela Universidade Estadual Paulista, Campus Rio Claro. Desde 2008 é Professor no Instituto de Geografia da Universidade Federal de Uberlândia UFU e docente do PPGeo-UFU. Atualmente, é tutor do PET-Geografia MEC/UFU, Bolsista MEC.

Av. João Naves de Ávila, 2121, Instituto de Geografia, Campus Santa Mônica, UFU, Uberlândia, Minas Gerais. CEP: 38.400-902

E-mail: mirlei@ufu.br

Recebido para publicação em junho de 2017 Aprovado para publicação em maio de 2018 